\title{
Libraries and Information Services in a Post-Technological Society*
}

Maurice B. LINE: British Library Lending Division, Boston Spa, England.

Technological imperatives will produce major changes in society in the future, as they have in the past. Post-technological society will affect the way we work, where we live, and how we spend our leisure. Changes in educational and research directions and in publishing and information delivery will affect the role and shape of the library of the future.

This paper covers ground trodden by several papers in the last two or three years. Its only justification is that it approaches the matter from a rather different angle than most, and that it may help to stimulate debate and, possibly, concerted action. It asks questions to which only tentative answers are given, and opens up issues that are left as loose ends. Readers can work out their own answers and tie up the loose ends in their own way. It is the questions and issues that are important-so important, and so urgent, that they cannot be ignored without great peril.

\section{THE POST-TECHNOLOGICAL SOCIETY}

By "post-technological society" I do not mean a society in which technology has fulfilled all that could be asked of it (and probably more than many want of it) and has no further use. I mean a society in which technology, specifically electronic technology, is fully integrated and accepted, but as the servant of society. It is not hard to find examples of society serving technology, or at least of technologists, and those who make money out of technology making other people serve it (or them) - just as in the Industrial Revolution people served machines, had their personal and social lives organized around machines, and were forced into a different way of living by machines. We are still feeling the effects of the massive changes brought

${ }^{*}$ The views expressed in this paper are those of the author and do not represent those of the British Library. A version of this paper was delivered at the ALA Annual Conference in San Francisco on June 29, 1981.

Manuscript received August 1981; accepted September 1981. 
about by the Industrial Revolution, but some countries, at least, have long reached a stage where they are no longer dominated by industry, and others are suffering from an actual decline in industry which may prove irreversible in the long term. To me a post-technological society means one that has gone beyond technology and progressed to the concept of society for society's sake. Since such societies will be attained much more quickly in developed rather than in developing countries, this paper is concerned with the former. The latter raise different and extensive issues which deserve separate discussion.

This paper will be at least as concerned with the social framework as with the role of libraries and information in a future society, since libraries and information cannot exist in a vacuum and must be geared to the society we have. They can respond to changes, often after some delay, as has happened too often in the past, or they can anticipate them, or they can perhaps influence them.

My own picture of a possible, and by no means improbable, future will be an optimistic one, in that I shall assume that no major wars or major social revolutions occur-only a gradual, but eventually massive, change.

\section{ECONOMIC SHIFTS}

The decline of heavy industry has been happening for a long time, even if allowance is made for the fact that some of its decline in developed countries has been caused by exporting it to developing countries. Big things are still made, but they are no longer made manually, since much of the heavy work has been taken over from men by machines-machines, moreover, that do not even have to be minded by men. Some industries are more amenable to this kind of change than others, but few if any industries are unaffected. These changes are being greatly accelerated by electronic technology.

Since there will be less work and economic growth will be slower, nil, or negative, the disposable income of the average citizen will increase slowly, remain steady, or decline. This will reduce buying power and affect production.

There has been a huge switch from production industries to service industries, which have absorbed many of the personnel freed from production industries. The service industries themselves are now being subjected to automation and this time there will be nowhere for people to go for jobs. The Western world may or may not achieve continued (or resumed) economic growth. If it does, it will be achieved largely by automated means. Some jobs will be created, but far from sufficient enough to replace all those destroyed. Without economic growth-and no economy can go on growing for ever-no jobs will be created. The question is not, therefore, whether but how fast jobs will be lost. Whatever measures may be taken to alleviate it, the loss of jobs will happen and the sooner we adjust to the fact the better. Jobs are being lost, now, in most of the developed world. It is 
later than we think, and planning and action are needed urgently.

\section{A WORLD WITH LESS WORK}

There are various ways in which the loss of jobs might be dealt with. One possibility is not to deal with it at all. The results of a do-nothing policy would be that a very large proportion of the population would be unemployed, and after a time unemployable because they become unused to working, and the gap between the rich and poor would extend to an unbridgeable width. The social and political dangers of such a situation are obvious: it could be controlled only by a system that would be dangerously near to a police state. The alternative is anarchy.

A positive alternative is to deliberately create work, in order to have full or near-full employment. Since there will not be enough necessary work, most of the work created will be strictly unnecessary. Some socialist states do this. Competition and enterprise are stifled, and awareness that their work serves no useful purpose can hardly satisfy those doing it. This is true even when systems are almost entirely manual; the problems of creating work when there is even less that needs to be done will be enormous. Technology could of course be ignored and systems left unchanged, in which case hard and unpleasant work will continue to be done by peoplework that could be done automatically. This could also be a cause of dissatisfaction.

Another alternative is to spread work around more thinly, so that, in effect, everyone works part-time. This solution requires full cooperation from the work force, and workers with full-time jobs have, to date, given no indication that they will behave altruistically.

We shall probably see a mixture of all these solutions: more people totally unemployed, more people working shorter hours than now, and some deliberate creation of work. Whatever happens, a lot more people will have a lot more time on their hands-except psychiatrists.

The work that will exist will be mostly skilled, and much of it will be highly skilled. Unskilled labor will be little in demand: this is the corollary of the otherwise wholly welcome decline in unpleasant work. It is incidentally a sad reflection on modern society that little attempt has been made to apply modern technology to some of the nastiest, dirtiest, most laborintensive jobs such as garbage collection-presumably because the workers in question have less say than middle-class housewives, much of whose time is now spent in waiting for labor-saving devices to be repaired.

\section{SOCIETAL DECENTRALIZATION}

Information technology will make our present huge conurbations unnecessary, and they will no longer exert a magnetic attraction because they will have no more work to offer than smaller communities, including probably small rural communities. Much work will be capable of being done without traveling to it. We may see a revival of small towns, on a 
truly human scale, where people know one another and feel some sense of responsibility to and for one another. Indeed, conurbations, many of which are historically amalgamations of small townships created largely by the Industrial Revolution, may break up again into small townships. Social life in such communities can flourish.

Huge industrial plants will not be necessary either. That is not to say that there will not be huge industrial concerns, but they will be able to consist of a network of small units, which can be semiautonomous and widely scattered. Within units, smaller groups can have their own identities. Since people find it very hard to relate to large numbers of other people from day to day-fifty is about the maximum meaningful grouping-this trend, which is already occurring in forward-looking industries, is entirely beneficial. It will make communication within firms, which is often lamentably poor at present, even more important.

A move from big cities to townships and other smaller communities, and the independence of distance provided by information technology, should lead to much greater local and regional self-sufficiency. More social selfsufficiency would certainly be expected, but political self-sufficiency, in the form of greater independence of national or state government, could also develop. There tend to be fashions in centralization and decentralization, and the recent trend towards decentralization may not last in the face of international tensions. The balance will always be a difficult and shifting one, but technology should enable national identity and purpose to coexist with a high degree of regional and local autonomy.

The need for balance between the state and smaller groups will also become greater as most Western societies come to be more and more multicultural, not to say multilingual. The cultural needs of minorities will have to be reconciled with the fact that they are part of a larger community.

\section{ALTERNATIVE LIFE-STYLES}

There are signs that some of the social changes suggested are already taking place. Beneath all the superficiality and sheer silliness of many "alternative" movements in psychology, politics, social life, etc., it is not hard to detect a deep and widespread desire for a less competitive, less aggressive, less exploitative, and less polluted society-one less dominated by industry and the profit motive. This desire, ill defined though it may be, is surely felt by many who play no part in these minority movements. We should incidentally remind ourselves that not all dropouts are failures: many could have succeeded in our society if they had wished and tried. There are signs of changes in education, too. Academic pressure on school pupils in Japan may have increased in recent years, but it has decreased in many countries, including Britain, partly because schoolchildren themselves have a different view of the future-less optimistic than in the past, but certainly less aggressive and self-seeking. 
Optimistic faith in technology generally is a thing of the past, except for those directly involved in technological developments. A feeling almost of despair on the part of many people, due partly but certainly not solely to technology and its misuse, is leading them to take up extreme positions. This is a dangerous trend: society rarely progresses by extremes or fluctuations between them. If mindless opposition to technology can be redirected to careful thought as to how technology could be used to benefit society, and if those who appear to have total faith in technology could bring themselves to think more of its social function, not only would the pro- and antitechnology split be healed but both sides could work toward a common end.

\section{NEW EDUCATIONAL NEEDS}

The economic and social changes outlined above will obviously create a need for very high skills on the part of a few. Skills of a lesser order will need to be much more widely disseminated, and some knowledge of electronic technology should be universal. The educational system will need to gear itself to this, not only during childhood and adolescence but during adulthood as well, since much of the population will need reeducating, maybe several times if not continuously.

Other educational needs are less obvious. One of the reasons why the idea of a society where there is less work horrifies us so much is that we have been brought up to worship work. Work worship is deeply ingrained in us-not surprisingly, as the prosperity of the Northern Hemisphere (and more especially, the northern part of that) has been built on the AngloSaxon Protestant work ethic-originally work to keep oneself warm, work to save one's soul, work to create wealth - and ultimately work as an end in itself. The right to work is in itself an odd phrase-why not the right to be idle? Because the right to be idle sounds immoral; laziness is one of the worst sins. I suspect sloth is probably rated, deep down, as the worst of the seven deadly sins - most of the others are fun, like gluttony and lust, or generally accepted as human weaknesses, like pride and envy. Historically, work worship is recent, and geographically it is not widespread. There will be no point at all in inculcating the work ethic in a society where there is not very much work. Instead, there is much to be said for inculcating a play ethic, or at least a leisure ethic. There will be a lot more leisure, and if soul-destroying work is not to be replaced by soul-destroying leisure, people will have to learn to enjoy it and use it positively. In the early stages this will require major efforts, because it will be unnatural both to the work worshippers and to the next generation of work shunners.

Since continuous expectations of an ever-increasing standard of living cannot be sustained, people will also need to be educated for contentment. They will have to learn to live more in the present, and there will need to be a certain degree of acceptance that things are as they are, economically at least. The hope that somehow, sometime, improved income, housing con- 
ditions, or whatever will make people happy will have to be abandoned. This does not of course mean an Oriental fatalism or a cessation of efforts to improve people's well-being; it does mean that these efforts should be personal and social rather than economic. A recognition of this can again be seen in the burgeoning of self-development and social growth movements, though many of these are too inward-looking, not to say egocentric, to be of much social value, even if and when they actually work.

\section{PLANNED LEISURE}

Leisure will need to be carefully planned if it is to take the place of work in satisfying some basic human and social drives. It will have to absorb energies, mental, physical, and social. It is interesting to note how mankind, as his society progresses well beyond the stage where it depends on hunting, shooting, and fishing, increasingly occupies his spare time in hunting, shooting, and fishing-and since these are often expensive pursuits it is those who are highest up on the economic scale who go in for them most. Both individual and social leisure activities will have to be planned and provided for. Individual leisure activities will of course include not merely mind-occupying (and mind-stultifying) things like Space Invaders but intellectual and artistic pursuits. Social activities, which will also be intellectual and artistic as well as sporting, will be especially important in the smaller communities we may hope to see replacing conurbations, especially as much work will no longer need to be done in groups and will take place in isolation-some of it at home. Individually and socially, the performing arts will gain in importance, and the development of creative talents of all kinds, from the making of furniture to the making of poetry, must be encouraged.

My earlier use of the term "necessary" in relation to work begged several questions. Some work is necessary to keep people alive, but merely being kept alive is hardly a sufficient objective for humankind: Man Cannot Live by Bread Alone. Other kinds of activity than work are equally necessary for a reasonably satisfactory human existence. This is recognized already to some extent, indirectly rather than specifically, by the increasingly large amount of work created by the leisure industry. Note the terms "work" and "leisure industry"- we even have to fit leisure into our work-oriented, industry-dominated ethos. In my (perhaps rather idealized) society the artist is as "necessary" as the coal miner, the sportsman as the government official.

\section{EDUCATION FOR FUTURE SOCIETY}

The tasks of education for future society are numerous and formidable. As well as meeting the continuing needs for scientific and technical knowledge and skills, education must educate people for leisure. This education must be both "positive" and "negative"- "positive" in developing social, 
physical, intellectual and artistic skills, "negative" in the sense that training for the rat race must be superseded by personal development for contentment. Certainly the present tendency of the educational system to stifle creativity and originality at an early age must be eliminated. All this is a very tall order, and to meet it may require radical changes in the system. Above all, the idea that education begins in infancy and ends in middle or late adolescence should be abandoned, because the kind of education needed in the future must be available at all ages. Education must be literally a continuous process, not a separate and definable chunk of life.

There is no reason why all education should be left to professional educators. Not only should people be encouraged to educate themselves, but they can educate one another. These processes go on all the time, of course, but they would benefit from some planning and professional help. The generation of educational materials- "educational" in the broadest sense-will be a major activity.

\section{GOVERNMENT AND PROFESSIONAL INFORMATION NEEDS}

Government, whether national, regional, or local, will have a massive and increasing need for information. Much of this will be of a technological, political, and economic nature, as it is now. If there is more local and regional autonomy, and some cultural autonomy, some of this information will be concerned with coordination, holding together as a nation a society that could easily become fragmented. Information will have to flow from, as well as towards, the center. The main dangers are that government's needs will be so huge that the information system will be designed primarily to serve them, possibly neglecting other needs; since much of the information transmitted to and generated by government will never appear as print-on-paper (POP), access to it will be almost impossible unless it is deliberately provided. Freedom of access to printed information is far easier to ensure and monitor than freedom of access to closed information stores. At the same time, access could be made much easier if governments so desired. This must be ultimately a political judgment, and will undoubtedly be a political issue: for better or for worse, politics and information will be even more inextricably mixed than now.

Service occupations, such as the medical profession, will also have a massive and increasing need for information, which should not be confined to any narrow specialism, such as surgery, but should encompass social aspects. Many wrong tacks have been taken because the context in which they were adopted was too narrow: a good example of this is the planning and building of high-rise flats. Such errors, which are colossally expensive in social as well as economic terms, are due partly to a failure of imagination but also to an insufficiently broad body of information; future doctors and planners working on a problem must be made aware of the wider framework of that problem. At the same time the background and 
nature of their plans and decisions must be made publicly available: they must convey information to the society they serve, abandon their mystique and expose themselves to public scrutiny. For this to be useful the public must have some understanding of what is being conveyed.

\section{CHANGING RESEARCH DIRECTIONS}

Development research will continue to be as important as it is now, but there will be much less fundamental research in science and technology because the funds will not be there, and such fundamental research as is carried out will tend to have its origin and inspiration in problem solvingthe problems set by government and industry, and, one must hope, society. The cutbacks in basic research we are seeing on both sides of the Atlantic, especially in academic institutions, are unlikely to be a temporary phenomenon. The cutbacks may be made by governments for economic reasons, but there is little resistance to them, partly because of a widespread public suspicion of science and technology. Research will of course still be done because some people like doing it and will have access to the necessary facilities, but there will be less of it, and it will become even more interdisciplinary than now-or rather, the present boundaries will give way to quite new ones, and science will be structured differently. Restriction of money and facilities will curb scientific and some social science research, but it need not seriously hamper research and private study in the arts and humanities, and in a leisured society one would expect the balance of research to shift substantially toward these subjects.

If my diagnosis and forecast are even approximately accurate, then we shall see a society in which there is less work, much less hard work, and shorter working hours; in which conurbations and large industrial concentrations are unnecessary and smaller communities and plants may take their place; in which there will be less centralization; in which services will grow and interact much more with the people they serve; in which fundamental research in science and technology will shrink, but private research in other fields will grow; in which, above all, there is far more leisure, and hence far more scope and need for leisure activities of all kinds. If we are wise, we shall adapt and develop education toward this sort of society; and in the process much education will be de-institutionalized.

\section{INFORMATION AND LIBRARIES}

All up to this stage is really an extended prologue to the setting of information and libraries in a broader context. I do not propose to spend long on likely developments in information technology, since it is becoming almost impossible to pick up even a newspaper without reading something about them. The vision of the "paperless society" is held out before us as an unavoidable and desirable ideal. Those who advocate such a society seem to me either naive or deliberately misleading. They speak as if all 
published literature were scientific and technical journals or report literature and as if all readers were involved in research and development. This is patently not the case, and if my predictions are correct scientific and technical literature will come to constitute a diminishing proportion of published material.

The advocates, moreover, appear to assume patterns of reading behavior-where, when, and how people read - that can hardly be widespread. For example, it is doubtful if many people read most books, apart from novels, in a linear fashion from the first page to the last, or read for long continuous periods, or do most of their reading, whether for the purposes of work or leisure, in only one or two places. I certainly do not, yet a system of "publication" based on electronic transmission and reception on a screen would impose these restrictions on me. My reaction would be the same as with microfilm - to get a legible hard copy as soon as possible to read when, where, and how I like. Unless very high quality receiver/printers are used, my copy may be legible but it will be much inferior to what I am used to, so that the new media will merely be an expensive way of producing inefficient old media. There will be even more paper around than now; it will simply be produced in vast quantities at the receiving rather than the producing end. Nor do I believe that economics favor, let alone necessitate, the electronic transmission of most published material: if enough copies of a document are produced at the receiving end it may even occur to someone that centralized production and distribution would be more efficient, and the book would be reinvented. The POP culture is likely to be with us for some time yet.

Are the paperless prophets offering yet another example of trying to do something because it can be done, of giving technology priority over society, which then has to adjust to the changes that technology has brought about? The adjustment would have to be not only individual but political, because paper is a democratic medium in that it can find its way almost anywhere it can be read, whereas electronic communication will tend to be elitist both within and between countries, widening the already huge information gap between developed and developing, rich and poor, north and south. The future will surely be a mix of more or less conventional publications - many of which may be produced from machine-readable versions by computer phototypsetting-and of electronically transmitted information-some of which will end up, and be distributed, as printed matter. Technology should be used to extend the range of media available, not reduce it, and it is more sensible to consider who needs what information before deciding that one mode of provision is inevitably best.

\section{NEW CONCEPTS OF PUBLICATION}

Nevertheless, the changes will be profound. The concept of "publication" will need to be redefined; it certainly cannot be confined to a printed document, or to any physical object at all. There will be no permanent 
archival form of many items, since the electronic originals of papers can readily be corrected, updated, or even deleted. (Incidentally, the danger that this will give governments or others the ability to control information and to reinvent the past as well as adjust the present cannot be ignored, and in an open society there must be strong safeguards). Some (by no means all) journal articles and reports, dictionaries, encyclopedias, and various kinds of handbooks are well suited to electronic storage and transmission. The contents of these materials too will be subject to frequent change.

Although most published material is likely to continue to appear in a more or less conventional form, the fact that much of it will be produced from a machine-readable version will mean that it need never go out of print because copies can always be produced on demand. So long as the electronic masters are kept somewhere, there will no longer be a need for permanent paper: books can be disposable objects. They have been regarded as disposable by many individuals for a long time-books are a rare example of an object which is consumed but after consumption is still there unless thrown or given away-but libraries have generally deplored selfdestructive paper and research libraries have avoided disposal whenever possible. If and when existing printed matter whose content is significant can be captured and converted to machine-readable forms, conservation efforts can be directed to works that should be preserved in their original form because of their artistic and literary value (Paradise Lost just doesn't look the same or communicate the same message in a seventeenth-century edition as opposed to a computer printout). Luckily, many such works were printed before the quality of paper began to deteriorate.

A leisured society, educated to entertain itself and to create, will produce more media, written, visual, and aural. Written media can of course simply be handwritten and duplicated for local distribution and use, and one would devoutly hope that most will stop at this stage. It will not be difficult, however, for authors to input their writings on word processors, and once they have done this there is, in theory, nothing to stop them from being added to larger files. Book publishing has always been a rather uncertain business, but at least somebody somewhere has had to make a decision on whether a given book was worth publishing. Who decides, and how, whether a book, or a short story, or a poem, is "worth" putting into a nationally accessible database? Will there be an equivalent of the book publisher in the form of a database provider, who may concentrate on a certain type or range of material and who will exercise some quality control over input? Or will input be relatively uncontrolled, and the control be exercised by the consumer, who will decide whether material and how long material remains accessible? There are obvious dangers in the latter. Similar considerations apply to research literature - whether and how input will be controlled, or whether and how control will be exercised by users. What does seem clear is that it will be very difficult to prevent rubbish getting into the system-even more than happens now. 


\section{BIBLIOGRAPHIC CONTROL}

In any case bibliographic control will be essential. Bibliographic control over conventionally published and printed material is far from complete or perfect, and this has not always mattered because there has been visual and physical exposure to the material itself. But with a closed store of information this kind of exposure is impossible. Solutions in the case of research literature should not be hard to find: most of it is readily indexable and exposure is important mainly for keeping up-to-date with general developments in and around one's specialty. With other kinds of literature, exposure may be achieved by means of television and videotex.

It is clear that while POP will continue to be published as now, it will increasingly be supplemented, and in some sectors supplanted, by alternative media. Alternative media will include videocassettes and sound recordings of various kinds as well as surrogates for POP. Some of the information on alternative media will be ephemeral-though no more than much present printed material-but much of it will be of long-lasting, if not permanent, interest. This will be especially true of the unprinted word-matter that would today be published as a journal article or report, but tomorrow may be accessible only electronically. The strange concept that appears to be held by many librarians that everything printed has permanent value and must be preserved while other communication media are largely disposable will become untenable (as it should already be-many books are of far less value, even as ephemera's of interest to future social historians, than many films or television programs).

\section{HOME INFORMATION SERVICES}

One obvious trend is that most homes in Western society will have (as they have now) television sets, and also videotex adaptations. Many homes will also have their own computer terminals. The average home may be poorer in real terms than now, but such equipment will be cheap and commonplace. In one way or another, many individuals will be able to call up a great deal of information without having to leave their houses, and some will be able to print it out.

It looks then as if there will be a greater volume of information generated at all levels, from government through academic and research bodies to individuals, in a wide variety of forms, with imperfect bibliographic control and only limited quality control. The information will range from that needed and generated by management, through research papers, to material produced for leisure-for the enjoyment or amusement of others or the satisfaction of the creator. Much of this information will be available on television, much on machine-readable databases some of which will be accessible in many homes, and much in conventional POP, which because it need not be permanent can be produced very cheaply and hence made available to a wide market. 
In this situation, the workers will be able to obtain the information they need for their work either at a place of employment where others work or at home if their work is such as can be done at home, whether online or from printed paper produced at a terminal. Their leisure needs, and the much greater leisure needs of the increasing numbers of unemployed, will be met by television, including videotex and videocassettes, and by cheap throwaway POP. So will their education needs-and I suggested earlier that education will involve many more people as educators as well as learners, that it will be lifelong, and that its strictly functional element will be limited and less socially important than its leisure element.

\section{INFORMATION SUPPLIERS}

Some of the information will be produced by government and made available as a public service if not a public necessity. It may or may not be supplied by the government, and even if it is, it may not be free. Some information will be produced by amateurs, whether groups or individuals, at their own initiative and expense-but access to it may still be paid for, partly depending on how it is supplied.

Some information will be produced for no direct payment (like research papers), but will be commercially supplied. Much will be both produced and supplied for profit. To state the obvious, someone will have to pay for the supply if not the production of all kinds of information, and if it is supplied electronically, particularly in direct response to demands, the costs cannot and will not be concealed. This would not need stating if much of the information supplied by and through libraries at present were not detached from any costs and prices. It has of course been paid for at one stage, usually from public or institutional funds, but uses are not paid for, and the consumer very rarely pays anything. This very point has, of course, led to the campaign by authors and publishers for so-called public lending rights and for photocopying fees. There are various answers that can be made to the arguments put forward, but most of these will be irrelevant to much information in the future because the supply of information, for each and every use, will be in the producers' or suppliers' hands and under their control. If they want to sell, say, a videodisc to an institution on terms that permit subsequent use without payment to them, that will be their decision-but in such cases the initial sale price will hardly be small.

\section{WHERE DO LIBRARIES FIT IN?}

Where might libraries fit into future society? The need for current recreational reading will be supplied (as now) largely by disposable paperbacks. Needs for publications of the past will be capable of being met directly by on-demand printing from a machine-held database, or possibly from microform. Reference needs, fulfilled at present largely by directories, handbooks, encyclopedias, etc., will be met online, probably through television screens. Research needs will be satisfied largely through commercial data- 
base operators, selling printouts or computer time. Libraries are intermediaries in the communication of information, at best transmitters: if intermediaries are less needed, and transmission is done in other ways, where do libraries come in?

Should libraries wait and see how things develop and then see what they can do about it? Should they try and influence matters at an early stage-if so, how, and is it already too late? Should libraries become producers as well as intermediaries? Should patrons be charged? All or some? If some, where should the line be drawn? The questions are agreed, but no one knows the answers.

Librarians who consider these matters tend to start from the assumption that public and other libraries exist, that they will still be supplying POP, and that the main issue is whether they add electronically accessible information to their services. An alternative approach would be to start with the "null hypothesis" that in the future libraries will not be needed-not even to supply books - and then to consider the best means of making information available in various forms. If the best means turns out to include something like libraries as we know them, at least they will be based on more secure foundations.

\section{THE INFORMATION UNIT}

In institutions such as industrial firms and universities there will almost certainly be an important role for an information unit-important if only because there will be such a quantity and variety of information, available in so many ways, that an access and control unit will be vital if users are to acquire the information they need and to acquire only the information they need-sipping or drowning, both inferior to a decent drink, will both be possible without expert help. Since conventional POP will still exist the information unit may as well acquire and provide that as well: note that the unit will be adding POP to electronically accessible information, not vice versa. A large store of books will be unnecessary, since only those needed fairly frequently need be kept for long; others can be obtained on demand as required. As well as remotely accessible information and POP, there will be local information stores held in electronically accessible form, whether built up locally or acquired as electronic packages (such as videodiscs or tapes containing the future equivalent of journals). The unit will supply both information, orally or on paper, and POP, much of which will be generated at terminals. There will of course also be local access points within an institution of any size, e.g., the chemists will have direct access to chemical data. The unit will have one very big advantage over local terminals in that it will be able to afford machinery to produce far higher quality POP.

The unit must also be able to supply remote workers, since many will not need to come into the institutional buildings regularly. The institutions will pay all necessary fees for the use of information, since their staff will 
presumably be using the information for the purposes for which the institution employs them. Whether the unit itself pays or whether it charges departments of the institution is a minor issue.

Information, in its widest sense, for the public is a rather different matter. Or is it? There may be terminals and screens at home, but the same problems of diversity and quantity of information sources and media will exist, perhaps on an even larger scale. There is no reason why there should not be-indeed, it is fairly certain there will be-various information suppliers, some of them competing with one another. The question is whether there is a place for a publicly-funded service embracing a wide range of information sources and media, and if so what form it should take. In the public interest, and ultimately in the national interest, ready access to official information should be provided, but this information could still be made available at home: a physical unit open to the public, on the lines of today's public libraries, would not be necessary.

The same applies to other information sources: there is a strong political and social case for a publicly-funded guidance unit, and probably also a supply unit, though it would not always be easy to decide when the supply costs should be carried on public funds on the grounds of public utility. A very strong case can be made for free, or at least heavily subsidized, access for deprived sectors of the community, but borderlines are no easier to draw here than elsewhere. Some people will have no television and no money to spend on books, and for these there could be places that were open to the public and where free and direct access could be provided. In this case the future equivalent of the public library would become a sort of information flophouse.

\section{COMMUNITY CENTERS}

Another approach is more promising. The growth and importance of leisure have been stressed several times in this paper. At first it will be enforced leisure, but one can also expect more voluntary, guilt-free leisure. It will be a matter of the utmost importance to provide leisure centers-on public funds, because the unemployed will not be wealthy. These would be community centers that would serve the functions of self-education and mutual education, creative activities, and individual and group recreation. All of these will need access to information of different kinds, and most of them will generate information as well. An information unit will therefore be an absolutely essential part of the community center. Some information will be produced for (and often by) groups rather than individuals: listening and viewing, retrieving and assessing information, are often better done in groups than individually. The Pompidou Centre in Paris may be more forward-looking than even its originators thought. Since the identity and coherence of the community will be very important, there will of course be no question of restricting it to one sector. Issues of 
who pays for what will still have to be resolved, but this will be a community decision.

In other words, something rather like the public library will have to be reinvented-but it will be necessary because it is vital to serve society, not because it happens to be there already. It would be rash to prophesy that community centers will be an inevitable element in future society, but it is hard to see how otherwise society can respond intelligently and humanely to the changes it will undergo. At the least, community information service and integration with education and leisure seem a more than worthy objective for the public library or its future equivalent. It is, moreover, an objective that the public library is in a good position to help achieve: it can give a lead as perhaps no other public service can. Finally, it is an objective that is as applicable to developing as to developed countries. The concept of a worldwide network of community information units is very attractive, and may not be as Utopian as it seems at first.

\section{NATIONAL CENTERS}

Has all this future-gazing anything to do with national libraries? This is another question that I would turn round, and, instead, ask, What national library/information service will be needed to serve future society? This question is too big to discuss just now. However, one function seems fairly certain - that of acting as a backstop reservoir for permanent storage and supply, in support of all the local and institutional units. This function will have to be applied selectively, and selection will be one of the most difficult problems to handle. To avoid corruption of records, they should be stored in a more "fixed" form than volatile electronic media-paper, perhaps? Bibliographic control-also selective-may also be a function, though the national center's role here may be mainly one of coordinating and standardizing rather than generating records.

Since the frontier between publishers and librarians, already subject to occasional frontier disputes, will become more and more fluid, and since both producers and disseminators are working towards a common end, separated only by the need to recover costs or make profits, not only should a truce be called between the parties but they must form an alliance. This will inevitably be somewhat uneasy - only a dead marriage has no tensions or conflicts-but continued warfare will incur penalties not only for the parties themselves but for society.

\section{LIBRARY EDUCATION}

Finally, and briefly, what kind of training will be needed for our future intermediaries? Even today I would like to see a much more broadly based course than conventional library education normally offers, one that is concerned with communications rather than librarianship and information technology - "communications" to include the whole field of publishing, bookselling, advertising, and communications technology. Future ed- 
ucation may need to be broader than this. Since such a course could not possibly be contained within three or four years, and since much of it anyway is relevant to much of the population, it would be diffused, spread over a large number of years, starting in childhood and continuing through life. The educators too will need to be diffused-we should all be educating ourselves and one another and it should no longer be a question of administrators retiring to stud in their latter years to produce people in their own image. Where expertise and special training will be needed is in information analysis and coding, even though one would hope and expect much of this to be done directly by the computer through analysis of the full original text.

\section{CONCLUSION}

Who will decide what happens? Not the technologists, one must hope, nor any sort of elite; though opinion may need to be led, this is different from decision making by a few for the many. Libraries and information people should obviously have a major say, and they may have to represent their users, present and potential. This implies that librarians must be fully integrated with the society they serve-just as doctors and planners should be, but so rarely are, integrated with the people they are supposed to be serving. Information, as perhaps the major national resource of developed countries in the future, must never become the domain of "experts". A massive and continuing process of discussion, leadership, and consultation with information users - most of them ordinary people-is necessary, and should begin now. Leadership of social trends is not a common or natural characteristic of the library and information profession, but it is desperately and urgently needed.

The post-technological society, to conclude, should see libraries and information services totally integrated into society in a way that we are only beginning to glimpse today. The implications of this are much more profound than this paper indicates, and the whole future system needs to be thought through in depth. If there is a single main message in this paper, it is that a technological vision alone is hopelessly incomplete, that librarians and information people must at all costs avoid the planning disasters that narrow-thinking, well-meaning experts have scattered so liberally around us, and that they can take a positive lead not only in developing libraries and information services for the future society but in helping to shape that society.

Maurice B. Line is director general of the British Library Lending Division at Boston Spa, England. 